\title{
A Study of the Mental Health and Psychological Hardiness of the Staff at the Pars Special Economic Energy Zone in Iran: A Cross-Sectional Study
}

\author{
Ahmad Hajebi, ${ }^{1}$ Habib Emami, ${ }^{2,}$ Mehrdad Hosseinzadeh, ${ }^{3}$ and Abdolmohammad Khajeian ${ }^{4}$ \\ ${ }_{1}$ Mental Health Research Center, Tehran Institute of Psychiatry, School of Behavioral Sciences and Mental Health, Iran University of Medical Sciences, Tehran, IR Iran \\ ${ }^{2}$ Tobacco Prevention and Control Research Center, National Research Institute of Tuberculosis and Lung Diseases (NRITLD), Shahid Beheshti University of Medical Sciences, Tehran, \\ IR Iran
3 Bushehr Petroleum Industry Health Organization, Bushehr, IR Iran \\ ${ }^{4}$ Bushehr Petroleum Industry Health Organization, Bushehr, IR Iran \\ ${ }^{*}$ Corresponding author: Habib Emami, Tobacco Prevention and Control Research Center, National Research Institute of Tuberculosis and Lung Diseases (NRITLD), Shahid Beheshti \\ University of Medical Sciences, Tehran, IR Iran. Tel: +98-9127147041; +98-2127122029, E-mail: emamihabib@yahoo.com
}

Received 2015 June 10; Revised 2015 October 18; Accepted 2015 November 7.

\begin{abstract}
Background: Psychological hardiness is a protective personality characteristic against life stresses that plays a major role in improving one's ability to cope with environmental pressures.

Objectives: Thus, the present study aimed to evaluate the mental health status, psychological hardiness, and the correlation between the two in workers of the Pars special economic energy zone in 2010 with a special emphasis on demographic factors, such as age, sex, marital status, job status, field of action, and job experience.

Materials and Methods: This was an analytical cross-sectional study conducted amongst 743 workers of the Pars special economic energy zone. Stratified sampling was carried out. Data were collected using a general health questionnaire, a psychological hardiness scale, and a demographic characteristics questionnaire. Frequency distribution, means and standard deviations (SD) were calculated; Spearman's $\rho$ test, Kruskal-Wallis, and Mann-Whitney U-test for evaluating the correlation between the variables were also used. The cut-off value for statistical significance was set at 0.05 or lower.

Results: Findings showed that the mental health score had significant but reverse correlation with psychological hardiness $(P=0.002$, $r=-0.50$ ). In $44 \%$ of the workers, the general health questionnaire score was higher than the cut-off point; the psychological hardiness score in this group of workers was also significantly lower than those with a mental health score below the cut-off point. This study also demonstrated that female gender, a younger age, being single or widowed, being a non-rotational shift worker, and working in the operational units were associated with poorer mental health and a lower psychological hardiness score.

Conclusions: Findings of this study showed the importance of psychological hardiness in maintaining mental health. Special attention should be paid to maintaining and improving the mental health of workers in the Pars special economic energy zone. One of the main principles involved in the sustainable and integrated development of a company is healthy human resources in all aspects, including physical, mental, and social health. Therefore, the current situation necessitates designing evidence-based interventions focusing on vulnerable subgroups.
\end{abstract}

Keywords: Mental Health, Psychological Hardiness, Shift Work, Rotational Work, Bushehr, PSEEZ

\section{Background}

Pars special economic energy zone (PSEEZ) is located in south of Iran. This area rose to fame earlier in the current decade following the discovery of a rich reservoir of natural gas in a field $105 \mathrm{~km}$ away from Iran's south coastline. This region is shared between Iran and Qatar and covers $9700 \mathrm{~km}^{2}$. Since the detection of this reservoir, Iran now controls $18 \%$ of all natural gas reservoirs in the world and is ranked second after Russia. In the first phase of development, the PSEEZ planned 12 gas processing plants and 15 petrochemical complexes that are scheduled to be established, along with a mix of light and heavy industries and their associated support facilities (1). Although this huge project brings lots of advantages, the large number of workers and technicians required for this field face unbearable working conditions superimposed upon the hardship of being away from their family and loved ones to work. These employees are at risk of developing many kinds of physical and mental conditions, especially psychological disorders.

The world health organization (WHO) defines health as a state of complete physical, mental, and social well-being and not only a lack of disease or disability. According to this definition, mental health is a state where one recognizes one's abilities, copes with daily life stressors, works effectively and beneficially, and plays a valuable role in one's community. The WHO defines mental health as a state of

Copyright (C) 2016, Health Promotion Research Center. This is an open-access article distributed under the terms of the Creative Commons Attribution-NonCommercial 4.0 International License (http://creativecommons.org/licenses/by-nc/4.0/) which permits copy and redistribute the material just in noncommercial usages, provided the original work is properly cited. 
Hajebi A et al.

psychological maturity characterized by maximum efficacy and satisfaction obtained through personal and social interactions and includes positive feelings and reactions towards oneself and others. Therefore, a person is considered mentally healthy when he or she demonstrates mental comfort and peace of mind, when his or her mental and behavioral characteristics do not cause any problem for others or for him or herself, and when he or she can be efficient in personal, familial, and social domains (2). Stewart, Reid, and Mangham (1997) reported productive social skills, effective social interactions, cooperation, adaptive coping mechanisms, and internal fortifying characteristics as signs of mental health (3). These characteristics have several constituents. Psychological hardiness is one of these constituents, and people possess it to various extents. The concept of psychological hardiness was initially introduced by Kobasa and Maddi (1977); hardiness is defined as a stable personality trait that consists of three basic components: commitment, control, and challenge (3). Hardiness is important not only in moderating the adverse effects of life stressors but also as an effective factor that plays a role in both creativity and progress (4). It is generally accepted that hardy individuals do not experience life events that are qualitatively different from those experienced by non-hardy individuals. However, the former are more likely to perceive the events they experience as positive and also to see themselves as being in control than are the latter $(5,6)$.

The first disposition of psychological hardiness is commitment, and it is defined as a tendency to involve oneself in the activities of life and to take a genuine interest in and possess a curiosity about the surrounding world; commitment is reflected by a sense of capability in confronting others and believing in trust, value, and importance of one's "self" in one's experiences (7). Unfortunate accidents eventually will be viewed as interesting or meaningful situations (8). People who have this characteristic are committed to various aspects of their lives, such as interpersonal and family relationships, and they feel responsible for them (9). Commitment shows one's capability to be involved in relationships $(8,10)$.

Control is another disposition of hardiness, and it means believing in the prediction and management of life events. It is defined as a tendency to believe and act as if one can use one's own effort to influence the events taking place around oneself (10). Having an inner sense of control increases one's ability to adequately respond to a stressful situation and helps a person to transform hard and difficult situations into manageable and tolerable ones by showing productive and desirable behaviors. In fact, through control, one can gain access to a valuable treasury of various reactions to confront the risks of stress (11).

Challenge is the opposite of fear and danger. A challenging disposition is defined as the belief that change, rather than stability, is the normal mode of life and constitutes motivating opportunities for personal growth rather than threats to security $(10,12)$.
Extensive evidence suggests that hardiness has a positive correlation with physical and mental health. In other words, this personal characteristic is a source of internal resilience and buffers the negative effects of stress and also prevents physical and mental disorders (12-15).

\section{Objectives}

This study aimed to evaluate mental health status and its correlation with demographic factors and psychological hardiness of workers in the PSEEZ. It set out to answer the question of whether psychological hardiness and some of the demographic factors can determine the vulnerability of staff. In other words, the authors would like to find out whether the aforementioned factors can predict which group of personnel is exposed to a greater risk and is therefore more vulnerable to stress.

\section{Materials and Methods}

\subsection{Participants}

The sample was composed of 745 workers who were selected from the petrochemical and gas industries. Sampling was stratified and convenient. Questionnaires were filled out from April to July of 2010. Informed consent was obtained from all participants who took part in this study. Employees with at least one year of work history from both sexes who agreed to participate in the study were included in the sample.

\subsection{Materials}

\subsubsection{Demographic questionnaire}

This questionnaire was designed by the researchers to collect the demographic data of the participants. The questionnaire included variables, such as sex, age, marital status, job situation, and field of work. For the job situation, we listed two categories: rotational and non-rotational workers. Rotational employees work continuously for two weeks and then have one week off. Generally, their families live far from the PSEEZ in other cities or even in other provinces. Non-rotational workers work five days each week and then have two days off on the weekend. Nearly all of their families live in the PSEEZ.

\subsubsection{General Health Questionnaire (GHQ)}

The GHQ was introduced by Goldberg as a method to identify non-psychotic mental disorders (16). This questionnaire has been employed by Goldberg and Hillier as a screening test for mental disorders. It consists of four subscales: somatic symptoms, anxiety, social dysfunction, and depression (17). In this study, we used the GHQ-28, which has four subscales with 7 questions each. Goldberg and Hillier reported a specificity of $82 \%$ for a score of 23 , which is used as a cutoff point (16). In 1996, It was demonstrated 
Hajebi A et al.

that at this cutoff point of 23 , the sensitivity, specificity, and total error were $88 \%, 79 \%$, and $16 \%$, respectively (17). The Cronbach's alpha was $88 \%$ in Goldberg and Hillier's study (16). The validity of the GHQ questionnaire has been evaluated, and the Cronbach's alpha was found to be 0.89 .

\subsubsection{Ahvaz Hardiness Questionnaire}

The Ahvaz hardiness questionnaire was designed in 1998 by Palahang et al. with the aim of creating a scale to determine the psychological hardiness of their understudy population (18). This questionnaire contains 20 questions, and the Cronbach's alpha is used to evaluate its internal consistency. The coefficients for the total sample size and also the male and female participants were $0.76,0.76$, and 0.74 , respectively. In order to determine the reliability of the instrument, this study was repeated after 6 weeks on 119 participants. Correlation coefficients between the participants' scores in the pretest and the second test were calculated as $\mathrm{r}=0.84$ for all participants, $\mathrm{r}=0.84$ for males, and $r=0.85$ for females (18). The Cronbach's alpha for the Ahvaz hardiness questionnaire was calculated as 0.94.

\subsection{Procedure}

The questionnaires were prepared and approved by administration. One researcher was in charge of administering the questionnaires at each center. A four-hour training workshop was offered, and then the understudy participants were chosen according to the instructions given. Participants were provided with information on the goal of the study and also regarding how to complete the questionnaire. After obtaining informed consent from the participants, the questionnaires were administered. Those who did not consent were excluded from the study.

\subsection{Data Analysis}

Data analysis was conducted using the statistical package for the social sciences (SPSS, version 17.0). To determine the normal distribution of data, the Kolmogorov-Smirnov test was used, and the normality of the data was rejected. Therefore, non-parametric tests were used to analyze these data. In this study, in addition to descriptive statistical analyses, such as frequency distribution, mean, and standard deviation, analytical statistics like the Kruskal-Wallis were used to compare the groups; the Mann-Whitney Utest was utilized for post hoc analysis. The Spearman's $\rho$ test was used to determine the correlation coefficient between the GHQ and the handedness scores. In all analyses, the critical alpha was set as 0.05 and lower.

\section{Results}

A total of 743 participants entered the study. Of these, 607 (83.3\%) were males and 515 (70.4\%) were married. The majority of participants (69.7\%) were employed in the operational units; $67 \%$ of them were under 35 years of age, and $35 \%$ were non-rotational shift workers. The age range was 20 - 59 years, with a mean of $33 \pm 7.35$ ).

The demographic characteristics of the participants and their mean scores and SDs on the GHQ and the psychological hardiness questionnaires are shown in Table 1.

Table 1. Mean Scores of the General Health and Hardiness Questionnaires Based on the Demographic Characteristics of Participants

\begin{tabular}{|c|c|c|c|c|c|}
\hline Variable & Total $(n=743)^{a}$ & GHQ-28 $^{\mathrm{b}}$ & PValue & Hardiness $^{b}$ & PValue \\
\hline Gender & & & NS & & NS \\
\hline Male & $607(83.3)$ & $23.17(11)$ & & $52.5(13.8)$ & \\
\hline Female & $122(16.7)$ & $24(11.4)$ & & $52.3(12.8)$ & \\
\hline Age & & & 0.003 & & 0.0001 \\
\hline$<35$ & $493(67)$ & $24.2(11)$ & & $50.3(13)$ & \\
\hline $35-49$ & $213(28.9)$ & $22.4(10.4)$ & & $55.5(13.8)$ & \\
\hline$>50$ & $30(4.1)$ & $17.5(9.5)$ & & $63.4(14.5)$ & \\
\hline Marital status & & & NS & & NS \\
\hline Married & $515(70.4)$ & $22.9(11)$ & & $53.4(14)$ & \\
\hline Single & $193(26.4)$ & $24.4(10.9)$ & & $50.3(13.4)$ & \\
\hline Divorced & $10(1.3)$ & $23.6(16.2)$ & & $50.3(9.9)$ & \\
\hline Widowed & $14(1.9)$ & $31(14.4)$ & & $47.8(10.6)$ & \\
\hline Job situation & & & NS & & 0.001 \\
\hline Rotational shift worker & $226(30.9)$ & $23.6(9.4)$ & & $51(13.3)$ & \\
\hline Non-rotational, non-shift worker & $174(23.8)$ & $23.3(13.4)$ & & $52.8(14.7)$ & \\
\hline Rotational non-shift worker & $256(35)$ & $22.5(10.4)$ & & $55.6(14.5)$ & \\
\hline Non-rotational shift worker & $76(10.3)$ & $25(9.8)$ & & $48.8(11.5)$ & \\
\hline Field of action & & & 0.04 & & NS \\
\hline Operational & $513(69.7)$ & $25.2(11.1)$ & & $52(13.6)$ & \\
\hline Logistic & $223(30.3)$ & $22.1(11.2)$ & & $52.7(14)$ & \\
\hline
\end{tabular}

Abbreviation: NS, not significant.

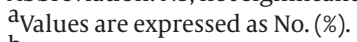

$\mathrm{b}_{\text {Values are expressed as mean (SD). }}$ 
Hajebi A et al.

The mean scores of the GHQ and psychological hardiness of the workers were calculated using the demographic characteristics. The mean score of the GHQ was greater in females $(24 \pm 11.4)$, while the psychological hardiness was stronger in males (52.5 \pm 13.8 ); however, these differences were not statistically significant.

A between-group analysis using the Kruskal-Wallis rho showed a significant association between age and GHQ (P $=0.00$ ). Pairwise comparison utilizing the Mann-Whitney U test revealed that the GHQ score of the workers aged 50 and over $(17.5 \pm 9.5)$ was significantly different from those under 35 years of age $(24.2 \pm 11, \mathrm{P}=0.001)$ and also those 35 - 49 years of age $(22.4 \pm 10.4, \mathrm{P}=0.009)$.

The mean score of psychological hardiness (63.4 \pm 14.5$)$ was higher in workers at least 50 years of age than the other age groups $(\mathrm{P}<0.001)$. The Kruskal-Wallis rho and Mann-Whitney U tests showed a significant difference in the mean psychological hardiness score among the three age groups: age $<35(50.30 \pm 13)$ vs. $35-49(55.5 \pm 13.80)$ (P $=0.000)$, age $<35$ vs. $\geq 50(0.000)$ and $35-49$ vs. $\geq 50(P$ $=0.008$ ).

Better GHQ and psychological hardiness scores were observed among married individuals. However, this difference was not significant. The highest GHQ score of $25 \pm 9.8$ and the lowest score of psychological hardiness $(48.8 \pm 11.5)$ belonged to non-rotational shift workers. The difference was not significant for the GHQ score but was statistically significant for psychological hardiness $(\mathrm{P}<$ 0.001). The Mann-Whitney U test indicated significant differences between rotational non-shift workers (55.6 $\pm 14.5)$ and two other groups: non-rotational shift workers $(48.8 \pm 11.5, P=0.000)$ and rotational shift workers, respectively $(51 \pm 13.3, \mathrm{P}=0.0003)$.

Our results also indicated that participants who worked in operational units had a higher GHQ score (52.2 \pm 11$)$ than the GHQ score of logistic workers $(50 \pm 11)(P=0.072)$ and a lower score of psychological hardiness (51.2 \pm 13.3$)$ than the logistic workers $(53.8 \pm 13.9)(\mathrm{P}=0.102)$. According to the results of the Mann-Whitney U test, these differences were not statistically significant.

The mean psychological hardiness score in workers with a high GHQ score ( $\geq 23$ ) was $45.2 \pm 12$, while that for those with a low GHQ score $(<23)$ was $56.8 \pm 12.5$. The difference was statistically significant $(\mathrm{P}=0.000)$.

Spearman's rho test also showed a reverse correlation between the GHQ score and the psychological hardiness score $(r=-0.50)$. This finding indicates that the mental health score decreases when the psychological hardiness score increases. This correlation was statistically significant $(\mathrm{P}=0.000)$.

\section{Discussion}

In this study, the mental health status was poorer and the psychological hardiness score was lower in some of the subgroups for specific demographic factors, such as those with a female gender, a younger age, who were single or widowed, worked non-rotational shifts, and also worked in the operational units. Based on the cutoff point of 23 for the general health questionnaire $(17,18)$, our findings revealed that $43.9 \%$ of personnel are at risk for mental disorders; therefore, they require psychological examinations and interviews. A lack of such skills can dangerously put workers' mental health at risk. Beasley et al. (2003) conducted a study on resiliency in response to life stress. They concluded that hardiness, coping styles, and stressful life experiences have a direct effect on mental health. In addition, psychological hardiness moderates or buffers the negative effect of adverse life experiences and reduces the risk of mental disorders (19). A lack of hardiness is negatively associated with maladaptive personality conditions, such as depression, anxiety, and guilt $(5,20)$. Therefore, the activity of fortifying one's internal abilities, like psychological hardiness, can act as a protective factor in this respect.

The comparison of the mean score of psychological hardiness between the group with a high GHQ score and those with a score lower than the cutoff point showed a significant reverse correlation. The mean score of psychological hardiness was lower in those with scores higher than the cutoff point. Shakeri-Nia and Mohammadpour (2009) demonstrated that psychological hardiness and resiliency are two important factors that can predict one's mental health status. They found that hardiness had a more profound effect on one's mental health than resiliency (21). In another study, Ramzi and Besharat revealed that hardiness increases one's level of psychological well-being through feelings of commitment, control, and challenges, along with coping skills (22).

Workers below the age of 35 years exhibited poorer mental health and lower psychological hardiness scores than their older counterparts. These workers typically possess less work experience and therefore are employed lower down in the ranks. These factors can expose such workers to higher levels of vulnerability. Work experience seems to moderate worker responses to negative events at work (23). In a study of more than 6000 postal workers, Hurrell et al. (1993) showed that as a person gains more work experience, job stressors lose their adverse effects on physical and mental health (24).

An analysis based on marital status showed that the mental health of married individuals was better than that of people in other subgroups of marital status. This difference might be due to the fact that married people tend to receive more social support than unmarried people. Chou and Chi (2001) demonstrated that married individuals imagine a higher level of social support for themselves compared to single ones, and this sense of social support acts as a protective factor to prevent the development of emotional problems, especially depression (25). In another study, Cohen and Wills (1985) reported that social support can have positive effects on physical, mental, and social health with both protective and fundamental effects (26). Stroebe et al. (2005) showed that 
Hajebi A et al.

social support can act as a moderator on adverse life events. In other words, people who benefit from social support are better able to cope with stressful life events and therefore recover more easily (27).

In our study, the mental health status of non-rotational shift workers was poorer than it was for people in any other group. It seems the combination of living in the PSEEZ along with shift work probably has the worst effect on the mental health of employees. Shift work induces job stress and has adverse effects on job safety. Evidence supports the fact that shift work is associated with sleep disorders, gastrointestinal problems, anxiety disorders, a lack of satisfaction, and an increased rate of job accidents $(28,29)$. Shift work also has behavioral effects on health and can change one's patterns of sleep and eating habits, increase alcohol and cigarette consumption, and intensify work-family conflicts $(29,30)$. On the other hand, the psychological hardiness of shift workers was lower. Consequently, these workers tend to approach stressful situations less actively, and they therefore use less effective ways of coping during a specifically stressful situation $(14,31)$.

Operational and administrative unit workers demonstrated no significant differences in terms of psychological hardiness score. However, in operational units, workers likely face higher levels of job stress and eventually experience poorer mental health and a higher risk of developing mental disorders. The investigation of adverse effects of job stress on the performance and health status of workers is a relatively new field of science, which has been debated since the early 1970s. During the last 40 years, a model of correlation between job stress, health, and job satisfaction has been presented by various researchers. This model was developed using a framework designed by Caplan et al. (32) and Cooper and Marshall (33). In this model, job-related stress is considered a situation in which the combination of work situations and job characteristics of personnel results in acute physical or mental disintegration. These acute reactions can result in illness if they remain prolonged.

The present study had some limitations that made its results tentative rather than conclusive. First, the predictive relationships between psychological hardiness and mental health were identified merely by analyzing selfreported questionnaires. Such data are not always highly congruent with data obtained through clinical interviews or structured instruments. Second, although this study used a reasonably large sample size, the sample was a convenient one, rather than one obtained using a random sampling procedure. Third, a small number of staff members did not have any interest in participating in our study. They believe that these kinds of studies do not offer any advantages for them. Therefore, the characteristics of these staff members could have been influential on the overall results had they been included.

The findings of this study revealed the importance of psychological hardiness in maintaining mental health.
There was a significant but reverse correlation between psychological hardiness and mental health score. Psychological hardiness as an internal resistance resource decreases the adverse effects of stress and prevents the development of physical and mental disorders. On the other hand, our findings indicated some of the demographic factors that can affect the vulnerability of the staff. Therefore, it is suggested that necessary steps be taken in order to improve and reinforce workers' coping mechanisms and psychological skills. These findings clearly indicate the need for more attention to the mental health of workers in the PSEEZ and also highlight the importance of a periodic screening in the region because work conditions in areas like the PSEEZ are unfavorable and require resiliency and problem-based coping mechanisms. It is recommended that workers be evaluated and screened at the onset of their employment and then periodically thereafter. A program for identifying vulnerable and at-risk workers according to the well-defined schedule during the job process will also need to be developed.

\section{Acknowledgments}

We wish to acknowledge the health, safety, and environment (HSE) departments of the petrochemical and gas companies at the PSEEZ whose kind cooperation made this research possible. We would also like to thank the PSEEZ for funding this project.

\section{Footnotes}

Authors' Contribution:Ahmad Hajebi developed the research idea, prepared the manuscript, and analyzed and interpreted the data. Habib Emami contributed to developing the design of the study and the questionnaire and carried out the statistical analyses and manuscript writing. Mehrdad Hosseinzadeh and Abdolmohammad Khajeian contributed to developing the idea for the project and interpreting the results.

Funding/Support:This study was supported financially by the Pars special economic energy zone (PSEEZ).

\section{References}

1. Jain K, Awasthi S, Kumar P, Somashekariah BV, Phani AR. Formulation and Pharmacokinetic Studies of Rapidly Dissolving Nanofibers. Middle-East J Sci Res. 2014;22(8):1176-80.

2. Brundtland GH. From the World Health Organization. Mental health: new understanding, new hope. JAMA. 2001;286(19):2391. [PubMed: 11712923]

3. Kobasa SC, Maddi SR. Existential personality theory. In: Corsini R, editor. Current personality theories. NY, USA: Peacock; 1977. pp.1-13.

4. Hekmati B. Study of assertiveness and relation with creativity among students in second year high school average in Tehran. Payam e Moshaver Journal. 2002;101:81-7.

5. Alexander DA, Klein S. Ambulance personnel and critical incidents: impact of accident and emergency work on mental health and emotional well-being. BrJPsychiatry. 2001;178(1):76-81. [PubMed:11136215]

6. Kobasa SC. Commitment and coping in stress resistance among lawyers. J Pers soc Psychol. 1982;42(4):707.

7. Tartasky DS. Hardiness: conceptual and methodological issues. Image J Nurs Sch. 1993;25(3):225-9. [PubMed: 8225356] 
8. Maddi SR, Kobasa SC. hardy executive.Illinois, USA: Dow JonesIrwin; 1984.

9. Low J. The concept of hardiness: a brief but critical commentary. JAdv Nurs. 1996;24(3):588-90. [PubMed: 8876420]

10. Kaiseler M, Polman R, Nicholls A. Mental toughness, stress, stress appraisal, coping and coping effectiveness in sport. Pers Individ Differ. 2009;47(7):728-33. doi:10.1016/j.paid.2009.06.012.

11. Huang C. Hardiness and stress: a critical review. Matern Child Nurs J. 1995;23(3):82-9. [PubMed: 7475329]

12. Brooks MV. Health-related hardiness and chronic illness: a synthesis of current research. Nurs Forum. 2003;38(3):11-20. [PubMed: 14603637]

13. Kobasa SC, Maddi SR, Zola MA. Type A and hardiness. J Behav Med. 1983;6(1):41-51. [PubMed: 6876154]

14. Kobasa SC. Stressful life events, personality, and health: an inquiry into hardiness. J Pers Soc Psychol.1979;37(1):1-11. [PubMed: 458548]

15. Florian V, Mikulincer M, Taubman O. Does hardiness contribute to mental health during a stressful real-life situation? The roles of appraisal and coping. J Pers Soc Psychol. 1995;68(4):687-95. [PubMed: 7738771]

16. Goldberg DP, Hillier VF. A scaled version of the General Health Questionnaire. Psychol Med.1979;9(1):139-45. [PubMed: 424481]

17. Yaghoubi N, Nasr M, Shah-Mohammadi D. Epidemiology of mental disorders in urban and rural City Some'esara of Gilan. Iran J Psychiatr Psychol (Andishe va Raftar). 1995;4:55-64.

18. Palahang H, Nasr M, Barahini M, Shah-Mohammadi D. Epidemiological study of mental disorders in Kashan. Iran J Psychiatr Psychol (Andishe va Raftar). 1996;4:19-27.

19. Beasley M, Thompson T, Davidson J. Resilience in response to life stress: the effects of coping style and cognitive hardiness. Pers Individ Differ. 20 03;34(1):77-95. doi:10.1016/S0191-8869(02)00027-2.

20. Murray RA. Interpersonal guilt and self-defeating behavior of foster youth. The Sciences and Engineering; 2005. Dissertation Abstracts International (Section B): the sciences and engineering; p. 5415.

21. Shakeri-Nia I, Mohammadpour M, editors. The relationship between psychological hardiness and resiliency and mental health in male climbers Rasht. Congress of Mental Pathology; University of Kurdistan. University of Kurdistan; 2009. 256 pp.

22. Ramzi S, Besharat MA. The impact of hardiness on sport achievement and mental health. Procedia - Soc Behav Sci. 2010;5:823-6. doi:10.1016/j.sbspro.2010.07.192.

23. Wanous JP. Effects of a realistic job preview on job acceptance, job attitudes, and job survival. J Appl Psychol. 1973;58(3):327. doi: 10.1037/h0036305.

24. Hurrell JJ, McIaney MA, Murphy LR. The Middle Years. Prev Hum Serv.1990;8(1):179-203. doi:10.1300/J293v08n01_12.

25. Chou KL, Chi I. Stressful life events and depressive symptoms: social support and sense of control as mediators or moderators? Int J Aging Hum Dev. 2001;52(2):155-71. [PubMed: 11352200]

26. Cohen S, Wills TA. Stress, social support, and the buffering hypothesis. Psychol Bull.1985;98(2):310-57. [PubMed:3901065]

27. Stroebe W, Zech E, Stroebe MS, Abakoumkin G. Does Social Support Help in Bereavement? J Soc Clin Psychol. 2005;24(7):1030-50. doi:10.1521/jscp.2005.24.7.1030.

28. ScottAJ.Occupationalmedicine:state of the artreviews.Philadelphia: Hanley and Belfus; 1990.

29. Scott AJ, Landow JL. Shiftwork. Effects on sleep and health with recommendations for medical surveillance and screening. In: Scott AJ, editor. Occupational medicine: state of the art review. Philadelphia: Hanley and Belfus; 1990.

30. Day AL, Chamberlain TC. Committing to your work, spouse, and children: Implications for work-family conflict. J Vocational Behav. 2006;68(1):116-30. doi:10.1016/j.jvb.2005.01.001.

31. Maddi SR. The story of hardiness: Twenty years of theorizing research, and practice. Consult Psychol J: Pract Res. 2002;54(3):173. doi:10.1037/1061-4087.54.3.173.

32. Caplan RD, Cobb S, French Jr JRP, Harrison RV., Pinneau Jr SR Job demands and worker health: Main effects and occupational differences.Washington DC: DHEW publication; 1975.

33. Cooper CL, Marshall J. Occupational sources of stress: a review of the literature relating to coronary heart disease and mental ill health. J.Occup Psychol. 1976;49(1):11-28. doi: 10.1111/j.20448325.1976.tb00325.x. 